warmly. Moreover, the government can create the sense of powerful people participation in practical.

\title{
0076 THE POWERFUL COMMUNITY NETWORK
}

A Namprasert* Correspondence: Kaosuankwang police station, Kaosuankwang police station, Kaosuankwang district, Khon Kaen province 40000, Thailand

10.1136/ip.2010.029215.76

Background Calamity crime and traffic accident have brought serious loss of community people for so long. Many savage and sensitive cases have caused for death or property damage and for mental health which is invaluable and lasts long time to be cured. Each year the government has to use a large amount of budget to solve the problems.

Methodology According to the rapid change of the world, there is different way to prevent the serious cases in community which called community network. The main reason is that people cannot wait for help from the government officer without doing something when the crime or accident occurs. Moreover, the number of police officer is not enough to take care in every part. The community network means that the volunteer which includes people from many parts such as school students, villagers, doctors and nurses or even monks. All of these have been leaded by the policeman who has functioned to protect life and property of people.

Result There are 1032 volunteer community guards to be the network members in Khao Suan Kwang district now. They are divided in many sections such as traffic police volunteer, community guard, student guard in school or youth guard in village etc. So the record of the illegal offender arresting can increase to $81.60 \%$. And the target case of drug and illegal weapon can be seized up to 181.2 compare with the former time. Moreover, there is no serious case in community after setting this network.

Conclusion Building up community network can make the community stronger. People can live together safely and 